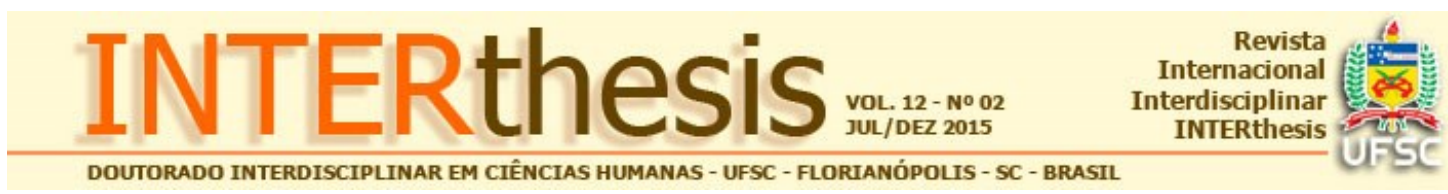

\title{
MODELOS ALIMENTARES E ARRANJOS PRODUTIVOS NO VALE DO RIBEIRA PARANAENSE: UM ESTUDO SOBRE OS PRINCÍPIOS DA SOBERANIA ALIMENTAR
}

Rubia Carla Formighieri Giordani ${ }^{1}$ Daniela Ferron Carneiro ${ }^{2}$

Maisa Santos ${ }^{3}$

Resumo:

Alessandro Donasolo ${ }^{4}$

A relação que se estabelece entre os mecanismos de produção, organização social e apropriação do espaço geográfico são fundamentais para a compreensão das práticas alimentares no meio rural. Este artigo traz à luz destas considerações, um estudo de caso sobre a soberania alimentar entre agricultores caboclos de uma comunidade situada na área rural do Vale do Ribeira paranaense. $O$ estudo demonstrou uma relação entre os aspectos organizacionais e econômicos da propriedade rural e a definição de certos modelos de consumo atestados pelas possibilidades produtivas. As modificações no perfil de produção agrícola como a redução do número de hortas, por exemplo, ou pouca variedade produtiva implicaram na diminuição do consumo de legumes e verduras, leite e carnes. Notouse ainda certa monotonia alimentar em parte influenciada pela pouca diversidade na produção de alimentos, com destaque para as frutas, verduras, raízes e cereais.

Palavras-Chave: Segurança alimentar. Agricultura familiar. Modelos alimentares. Arranjos produtivos.

\section{INTRODUÇÃO}

Embora o ato alimentar seja uma necessidade humana básica imprescindível à sobrevivência e reprodução da vida, o que se escolhe e se define como comestível ultrapassa o papel biológico do alimento e o seu valor nutricional (FISCHLER, 1995). A alimentação humana desencadeia processos e relações sociais que forçosamente tem implicações simbólicas e sociológicas na vida humana (POULAIN, 2013). O ato

\footnotetext{
${ }^{1}$ Doutora em Sociologia pela Universidade Federal do Paraná e doutora em Etnologia pela Université Paris Ouest Nanterre, França. Professora do Departamento de Nutrição da Universidade Federal do Paraná e pesquisadora do Grupo de Pesquisa em Sociologia da Saúde/Universidade Federal do Paraná-CNPq, Curitiba, PR, Brasil E-mail: rubiagiordani@gmail.com

${ }^{2}$ Mestranda do Programa de Pós-Graduação em Segurança Alimentar e Nutricional da Universidade Federal do Paraná, Curitiba, PR, Brasil. E-mail: danifercarneiro@gmail.com

${ }^{3}$ Mestranda em Ciência do Solo pela Universidade Federal do Paraná, Curitiba, PR, Brasil. E-mail: maisa agro@yahoo.com.br

${ }^{4}$ Engenheiro Agrônomo pela Universidade Federal do Paraná. Especialização em Educação do Campo e Agricultura familar e camponesa pela Universidade Federal do Paraná, Curitiba, PR, Brasil. E-mail: adonasolo@hotmail.com
}

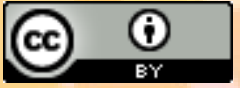
Esta obra foi licenciada com uma Licença Creative Commons - Atribuição 3.0 Não Adaptada. 
alimentar necessário à reprodução da energia da vida se repete infinitamente em toda e qualquer sociedade, entretanto a seu modo, cada grupamento humano desenvolve processos e concatena atividades com a finalidade nutricional (MINTZ, 2001).

Estas atividades, no caso específico das sociedades capitalistas, tem evoluído historicamente para confluírem em cadeias produtivas cada vez mais complexas contando a seu favor com a ciência e a técnica (HERNÁNDEZ, 2005; PLOEG, 2008; RADOMINSKI, LEAL, 2011; FERREIRA, 2012). Na lógica deste sistema, o valor do alimento, fetichizado, ultrapassa o valor de uso e todo o dispositivo e a energia para movimentar as engrenagens do sistema fundamenta-se na acumulação do capital (OLIVEIRA, 2002; CAMPOS, 2006; CAMPOS, CAMPOS, 2007).

A modernização conservadora no campo e a incorporação do capital financeiro na agricultura (DELGADO, 2001, 2005) irão provocar progressivamente intensas modificações territoriais - políticas e sociais -, sobretudo em camponeses originários, como é o caso das populações caboclas. Esta face do capitalismo no meio rural brasileiro, a partir da década de 1980, surgiu no modelo do agronegócio normalmente associado a grande propriedade, à monocultura de commodities, atrelando à produção um sofisticado conjunto de técnicas e conhecimentos que envolvem genética e química biológica (ELESBÃO, 2007; MIRANDA ET AL, 2007; WANDERLEY, 2011; RADOMINSKI, LEAL, 2011; FERREIRA, 2012). O que se observa no espaço rural brasileiro é que este processo de territorialização do capital e sua concentração implicaram em acirramento das desigualdades em muitas regiões, especialmente para os agricultores camponeses descapitalizados e nãotecnificados que mantiveram-se à margem deste processo (ELESBÃO, 2007; MIRANDA et al, 2007; WANDERLEY, 2011). Segundo Delgado (2005, p. 68) na "perspectiva do campesinato ou da agricultura familiar não integrada nas cadeias do agronegócio - que opera fora de uma estratégia tipicamente capitalista" decorre o aumento de sua "distância econômica e social entre esse setor e o agronegócio" (p.69).

Contudo, a agricultura camponesa e familiar, contrasta em sua lógica contrahegemônica e os agricultores familiares resistem em cumprir o simples papel de elo 
nas diferentes etapas da cadeia produtiva (CAMPOS, CAMPOS, 2007; PLOEG, 2008; SCHNEIDER, 2010). O meio rural se configura como espaço produtor de modos particulares de vida e de cultura em que o alimento exprime uma rede de conexões subjetivas e simbólicas entre pessoas, processos produtivos, as tradições comunitárias e questões do território (BRANDÃO, 1989; TEDESCO, 2011; WANDERLEY, 2009, 2011).

A característica principal do camponês gravita em torno de sua possibilidade de reprodução social pela unidade familiar, e o processo de trabalho configura-se na produção direta dos seus meios de vida, ou seja a terra (mesmo que não detenha a propriedade legal da mesma, como é o caso do grupo rural aqui estudado) (WOORTMANN, 1995; MARTINS, 1979). A lógica de sua economia familiar está pautada no suprimento dos mínimos vitais segundo Cândido (1971) ao invés da acumulação, ainda que estas necessidades sejam produzidas social e culturalmente.

Mesmo que o termo camponês seja empregado para se referir aos pequenos produtores rurais em que a família se configura como a unidade básica de reprodução social e econômica que destina parte de sua produção para o consumo interno da unidade familiar e eventual excedente para troca ou comercialização (SHANIN, 1980; WOORTMANN, 1995), há, no entanto, uma "grande diversidade cultural e sociopolítica das pessoas inseridas nesta categoria, e das mudanças causadas pelo processo de globalização contemporâneo na identidade, movimentação espacial e mobilização social e política” (SILVA, MURRIETA, 2014, p.39).

Os agricultores caboclos que residem na região do Vale do Ribeira paranaense, e que foram o foco de nosso estudo, guardam certas afinidades de outros grupamentos sertanejos, caipiras e caiçaras descritos por autores como Brandão (1981), Woortmann (1995), Fraxe (2004), Silva, Murrieta (2014), Queiroz (2006), Cândido (1971), Willems (2009). Assemelham-se em suas formas de organização social (como sistemas de intermediação e apadrinhamento), práticas sociais e cognições peculiares pautadas por matrizes de pensamento enraizadas na memória social, a valorização da tradição oral, além da manutenção do grupo doméstico e valorização da esfera comunitária da vida social. 
Atendendo os aspectos teóricos mais gerais da categoria analítica capesinato, busca-se, contudo considerar toda a heterogeneidade cultural e de sistemas sociais abrigados no interior dos espaços rurais. Posto isso, se acrescenta que "é a natureza das suas relações com 0 ambiente físico e suas implicações na constituição das atividades de subsistência e na tecnologia, bem como das próprias configurações socioculturais" (SILVA, MURRIETA, 2014, p. 40) que guardam relações com a abordagem das modificações no espaço e paisagem, no modo de vida e alimentação desencadeadas a partir do avanço do capital no campo.

Neste movimento histórico do capitalismo, novas configurações territoriais engendram dinâmicas sociais distintas dos sistemas de vida culturalmente referenciados implicando na reordenação do tempo/espaço e no conjunto de atividades que envolvem a lida com a terra, a relação com a natureza e a produção. São estas novas configurações do território constituído por diversos sistemas de relações (sociais, econômicas e simbólicas), as engrenagens fundamentais envolvidas na (re) definição de modelos alimentares tanto no meio rural quanto urbano.

Para explicar melhor as dimensões envolvidas na alimentação, Poulain (2003), trabalha com o conceito de Espaço Social Alimentar, como uma zona de liberdade de escolhas alimentares situado na relação entre a esfera biológica e a ambiental. Esta dupla série de condicionantes se afetam mutuamente e atuam como vetores que tensionam o espaço decisório das práticas alimentares. Além do fator simbólico que interfere nas práticas do grupamento, outras limitações são impostas pelo meio; no caso das sociedades capitalistas "se transformam em condicionantes econômicas" (ibidem, p. 251) e no controle tecnológico da natureza. São ainda as características sociais, a lógica da economia política que fundamenta o modo de produção de bens materiais e imateriais e que, por sua vez atuarão de forma decisiva na zona de escolhas alimentares do grupo.

Depreende-se daí que as práticas alimentares devem ser tratadas na sua interdependência entre os sistemas ecológicos, econômicos e simbólicos que estruturam as bases dos modelos alimentares. Portanto, a relação que se estabelece entre os mecanismos de produção e organização social e apropriação do espaço geográfico são fundamentais na delimitação de práticas alimentares. 
Nesta rede de inter-relações articula-se, portanto, à segurança alimentar, o conceito de soberania alimentar que traz em cena o direito humano à alimentação adequada sem extrair do debate o contexto da produção de alimentos (BRASIL, 2006; CONSEA, 2007; CAMPOS, CAMPOS, 2007; ABRANDH, 2010). Estas ideias implicam em problematizar os pressupostos e mecanismos pelos quais o alimento é produzido colocando a discussão científica da formação das práticas alimentares em um cenário de decisões políticas.

Este artigo traz à luz destas considerações, um estudo de caso de uma comunidade rural situada no Município de Itaperuçú, no Vale do Ribeira paranaense. Ao longo do texto far-se-á o exercício descritivo de articular elementos que concernem ao território e seus usos, os arranjos produtivos e organização social do trabalho às prováveis implicações nos modelos alimentares de agricultores caboclos.

O método para a coleta de dados foi delineado considerando-se o caráter interdisciplinar do objeto da pesquisa, bem como o contexto de imersão dos pesquisadores na comunidade estudada. Tendo em vista que a realização desta pesquisa foi viável em decorrência de atividades de extensão que objetivavam fortalecer economicamente os agricultores para a promoção da segurança alimentar, todas as etapas da pesquisa foram norteadas pelos pressupostos da pesquisa-ação (FREIRE, 2001; THIOLLENT, 2004). Por intermédio de abordagem social qualitativa (MINAYO, 2010) procedeu-se à observação participante complementada por entrevistas semi-estruturadas (SERAPIONI, 2000), questionários sobre Arranjos Produtivos e questionários estruturados sobre Frequência de Consumo Alimentar. As entrevistas e questionários foram aplicados mediante visitas domiciliares, optando-se pela aplicação do questionário de Frequência de Consumo Alimentar e a entrevista semi-estruturada entre as mulheres da casa, e o questionário sobre os Arranjos Produtivos realizado entre os homens. No total foram produzidos 24 questionários sobre a frequência e 27 questionários sobre a produção.

Este conjunto de instrumentos serviu para os propósitos de conhecer a base da alimentação das famílias, a forma como estas organizam a produção agrícola e realizar um diagnóstico da dinâmica do consumo alimentar da comunidade em relação aos produtos oriundos das roças, hortas e quintais. Sobre o formulário dos Arranjos Produtivos, não foi possível analisar o fator área da propriedade, uma vez 
que cerca da metade dos entrevistados não sabia especificar o tamanho da mesma. Assim, os itens analisados foram a organização do núcleo familiar quanto à mão-deobra na produção agrícola, a diversidade de produção e a destinação para o consumo interno da unidade familiar.

\section{SEGURANÇA E SOBERANIA ALIMENTAR: UMA BASE PARA O DEBATE DOS MODELOS ALIMENTARES}

O conceito atual de Segurança Alimentar e Nutricional praticado no Brasil abrange a indissociabilidade e o atendimento integral das necessidades básicas para assegurar uma vida humana plena e digna. Engloba o acesso físico e econômico, regular e permanente aos alimentos seguros do ponto de vista higiênicosanitário, livre de contaminantes químicos e nocivos à saúde. Refere-se ainda ao alimento produzido de forma saudável, baseado em um modelo de produção sustentável, seguro do ponto de vista ambiental além de culturalmente referenciado (VALENTE, 1997; BRASIL, 2006; CONSEA, 2007).

A Segurança Alimentar engloba o Direito Humano à Alimentação Adequada (DHAA), direito humano universal, ligado à própria realização da vida e "realiza-se quando cada homem, mulher e criança, sozinho ou em companhia de outros, tem acesso físico e econômico, ininterruptamente, à alimentação adequada ou aos meios para sua obtenção" (Pacto Internacional dos Direitos Econômicos, Sociais e Culturais (PIDESC) apud ABRANDH, 2010, p. 15). A realização do DHAA não está restrito ao aporte mínimo de nutrientes necessários para a manutenção da vida humana, mas compreende o direito ao acesso físico e econômico ao alimento de qualidade (VALENTE, 2002). Em um sentido mais amplo diz respeito ainda à adequação da dieta humana a um conjunto de questões de ordem ambiental, social e cultural (ONU, 1966; UNESCO, 2005).

O direito à alimentação e à nutrição humana estende-se ao direito de acesso aos recursos e mecanismos de adquirir e produzir os alimentos seguros do ponto de vista ambiental, sanitário e nutricional. Neste sentido o modelo de desenvolvimento rural e a modernização conservadora da agricultura brasileira com a expansão do agronegócio e das formas privadas de apropriação dos recursos naturais têm sido um obstáculo à concretização do DHAA (VALENTE, 2002; MALUF, 2007). 
A segurança alimentar implica no acesso contínuo e permanente ao alimento, inclusive para as gerações futuras. Liga-se, portanto à noção de sustentabilidade e à forma de produção dos alimentos no sentido da utilização adequada dos recursos naturais não renováveis de forma a assegurar a sustentabilidade da produção e qualidade de vida para gerações futuras (JUNGES, 2014; SCHRAMM, 2014).

Os preceitos da Segurança Alimentar e Nutricional tensionam, portanto, o modelo atual de produção de alimentos na medida em que a estrutura agrária, a tecnologia da empresa rural representam mecanismos hegemônicos de atuação do capital no campo (MIRANDA et al, 2007). À etapa anterior da garantia do acesso permanente e regular de alimentos seguros e saudáveis, a produção social e ambientalmente sustentável nos contextos culturalmente referenciados pelo camponês são a base da produção dos alimentos na ótica da Segurança Alimentar.

Em complementaridade à Segurança Alimentar, principalmente no que se refere às relações econômicas internacionais envolvidas na produção dos alimentos, encontra-se o conceito de Soberania Alimentar. Este conceito, segundo a definição do Fórum Mundial sobre Soberania Alimentar realizado em Cuba em 2001 trata do:

[...] direito dos povos de definir suas próprias políticas e estratégias sustentáveis de produção, distribuição e consumo de alimentos que garantam o direito a alimentação para toda a população com base na pequena e média produção, respeitando suas próprias culturas e a diversidade de modos camponeses, pesqueiros e indígenas de produção agropecuária, de comercialização e de gestão dos espaços rurais, nos quais a mulher desempenha um papel fundamental. A soberania alimentar favorece a soberania econômica, política e cultural dos povos. Defender a soberania alimentar é reconhecer uma agricultura com camponeses, indígenas e comunidades pesqueiras, vinculadas ao território; prioritariamente orientada a satisfação das necessidades dos mercados locais e nacionais. (CAMPOS, 2006, p. $154-155$ )

Assim, a Soberania Alimentar marca o direito das nações e dos povos de produzir, transformar, distribuir e consumir os alimentos de acordo com bases sustentáveis que respeitem as características sociais e culturais das suas populações. Esse conceito complementa a Segurança Alimentar e Nutricional, e ambos fazem parte do Direito Humano à Alimentação Adequada.

A soberania alimentar marca uma posição em relação às formas econômicas, organização social e referências culturais pelas quais os alimentos são produzidos. Atesta a necessidade trazer para o debate político o direito à autonomia, 
autodeterminação e viabilidade de formas da agricultura camponesa (FURTADO, BEZERRA, 2014).

\section{UMA BREVE ANÁLISE DO ESPAÇO: O RURAL DO VALE DO RIBEIRA}

O Vale do Ribeira é uma região geográfica localizada entre o leste do Estado do Paraná e do sudeste do Estado do São Paulo, numa área total de mais ou menos 24.193 quilômetros quadrados, compreendendo em sua extensão 32 municípios, sendo 25 municípios de São Paulo e 07 municípios do Estado Paraná (BRASIL, 2015). Trata-se da maior área contínua de Mata Atlântica do Brasil e onde está localizada a bacia de drenagem do rio Ribeira de lguape que nasce no Paraná e deságua em São Paulo (SIMÕES, LINO, 2002).

Os municípios paranaenses da região apresentam índices de desenvolvimento humano (IDH) abaixo das médias nacionais, e de forma geral índices de baixa escolaridade e analfabetismo, baixos índices de rendimentos e desigualdade de renda que superam em muito a média estadual (IPARDES, 2013).

O povoamento é considerado bastante antigo, de colonização europeia iniciada no século XVI e igualmente expressiva quantidade de remanescentes de quilombolas formados a partir do século XVIII às margens do rio Ribeira por escravos foragidos, libertos ou abandonados (QUEIROZ, 2006; PEDROSO JUNIOR et al, 2008). O Vale se caracteriza por áreas de grande isolamento dos habitantes principalmente na zona rural. Na década de 60 e70, a região recebeu investimentos do governo com abertura de estradas e expansão da rede de telecomunicações, porém esses incentivos não beneficiaram as zonas mais afastadas dos núcleos urbanos, além desencadearem resultados negativos em decorrência dos incentivos fiscais e outros benefícios para a exploração agropecuária que levaram a conflitos pela posse da terra (QUEIROZ, 2006; ANTUNIASSI, REISMANN, 2001).

Os municípios da região têm suas economias atreladas a agricultura familiar e a extração mineral. As atividades agrícolas com destaque na região são as culturas de banana, tangerina, caqui e maracujá e a pecuária bovina e bubalina. A extração de calcário representa uma atividade industrial importante da região, apesar do alto impacto ambiental negativo (IPARDES, 2013).

R. Inter. Interdisc. INTERthesis, Florianópolis, v.12, n.2, p.156-179, Jul-Dez. 2015 
A cidade de Itaperuçu, localizado na região de abrangência parananense do Vale do Ribeira, segundo dados de 2014 do IBGE, tem uma população de 26.371 habitantes (IPARDES, 2015) e no ranking divulgado pelo Programa das Nações Unidas para o Desenvolvimento - PNUD, o IDH da cidade é de 0.637 (IPARDES, 2015), destacando-se dentre os menores IDHs das cidades brasileiras.

De acordo com o Censo Agropecuário, entre os principais produtos produzidos no município de Itaperuçu estão o milho, o feijão, a mandioca, a cana de açúcar, a batata doce, o arroz e o tomate. As culturas permanentes presentes são tangerina, laranja, abacate e limão. Na produção animal, em ordem decrescente está a pecuária, a avicultura e suinocultura. A extração vegetal e a silvicultura estão aumentando significativamente na região, tendo a madeira de lenha e madeira para carvão vegetal os principais produtos do extrativismo. Entre os produtos obtidos pela silvicultura se encontram as madeiras em tora para papel e celulose, a lenha e a madeira em tora para outras finalidades (IPARDES, 2015).

A economia do município de Itaperuçú é essencialmente rural. Nos últimos anos vem sendo desenvolvida a produção de pinus em larga escala ocorrendo uma grande demanda por áreas de plantio e mão-de-obra não-especializada. Estes fatores estão levando uma grande parte dos pequenos agricultores a parar de produzir alimentos, inclusive para o consumo destinado à unidade familiar, e migrar para o trabalho assalariado.

Muitos agricultores têm arrendado suas terras para a produção de pinus, perdendo assim sua característica principal de agricultor familiar e passando à condição de operário rural. A migração da mão de obra masculina para a plantação e extração de pinus, além da venda e arrendamento de terras às empresas, ocasionou gradativamente a diminuição das áreas plantadas, além de trazer implicações nos hábitos de vida e consequentemente nos modelos alimentares. A alimentação no meio rural em regiões pobres pode ser mais monótona e vulnerável a oscilações, estações e restrições ecológicas. No caso destas comunidades de Itaperuçú, a produção voltada para o consumo interno da unidade familiar vem progressivamente sendo substituída pela incorporação de produtos alimentares transformados provenientes da agroindústria, com acelerado incremento nas dietas familiares de produtos industrializados, produzidos e comercializados por uma 
estrutura em rede que concentra o processo alimentar.

De outro lado, estas transformações econômicas vem acompanhadas de um esgotamento progressivo de recursos naturais ameaçando cada vez mais as paisagens naturais pelo uso intensivo de recursos naturais não renováveis (CAMPOS, CAMPOS, 2007). No caso específico do cultivo de pinus nas regiões do Vale, estas áreas imensas destinadas para a silvicultura têm sido chamadas de desertos verdes.

O processo de territorialização do capital no Vale do Ribeira forja-se neste setor do agronegócio em que o desenvolvimento se dá de forma desarmônica e caracterizado pelo paradoxo do acirramento da pobreza e da insegurança alimentar, além da apropriação intensiva dos recursos ambientais não-renováveis (CAMPOS, CAMPOS, 2007).

\section{CARACTERIZANDO OS ARRANJOS PRODUTIVOS}

A agricultura familiar na comunidade do Caçador se organiza pelos 27 núcleos familiares tendo como característica principal a produção para o consumo interno, com pouco excedente destinado para comercialização. Em casos excepcionais há excedente de produção comercializado na própria comunidade, como ocorre com o feijão, milho, citros, batata doce, mandioca e tabaco beneficiado. A maioria dos agricultores da comunidade encontra-se descapitalizada com pouco recurso para investir em benfeitorias na unidade de produção familiar e nenhum capital de giro. Há grande dificuldade de escoamento da produção pela falta de meios de transporte que é agravada pela topografia acidentada aliada à falta de conservação das estradas.

A comunidade se caracteriza pela divisão de uma propriedade entre dois ou mais núcleos familiares ligados por relações de parentesco. Normalmente, os núcleos familiares agrupam duas a três famílias (pais e filhos solteiros) em diferentes casas, podendo-se encontrar a casa dos progenitores e a casa dos filhos casados com suas respectivas famílias.

A sistematização dos dados obtidos a partir dos questionários sobre arranjos produtivos mostrou que existe uma variedade quanto à situação legal da propriedade rural. Apenas $35 \%$ das famílias possuem o registro legal da R. Inter. Interdisc. INTERthesis, Florianópolis, v.12, n.2, p.156-179, Jul-Dez. 2015 
propriedade; as demais se encontram à espera do processo de inventário (40\%) ou não apresentam registro de posse do terreno, visto que moram em terras arrendadas (25\%). Salienta-se que a maior parte das famílias que reside em terras arrendadas, não possui contrato lavrado com o proprietário.

O arrendamento não fica restrito ao aspecto financeiro e econômico regulada pelo mercado, outrossim, envolve relações morais percebidas não apenas como negócio, mas representadas como favores e assistência. Estas relações tensionam as esferas produtivas, uma vez que bloqueiam atividades agrícolas para certas famílias que vivem em terras arrendadas, haja vista as restrições impostas pelos donos da propriedade. Contudo, as contradições são ressemantizadas pelo laço afetivo, e a maioria dos arrendatários exprime esta relação com os proprietários como apadrinhamento e identificando-os como "pessoas a quem se pode recorrer na necessidade". A dependência envolve a detenção da terra e as mercearias de vendas de alimentos. Muitas delas funcionam também como um micro banco informal, correspondendo à "prática do caderninho" para a concessão de crédito.

Os núcleos familiares apresentam estrutura familiar tradicional. A idade e número de integrantes das famílias são variáveis; a escolaridade média é a quarta série do ensino fundamental, e na grande maioria os integrantes dos núcleos familiares são naturais da comunidade ou da região.

Há diferenças na dinâmica social entre os núcleos quanto aos responsáveis pela atividade agrícola da propriedade, podendo envolver todos os integrantes (pai, mãe e filhos jovens e adolescentes), ou apenas o homem mais velho (pai) ou a mulher (mãe) no manejo da produção. As mulheres mais velhas em geral têm uma vida social restrita ao âmbito doméstico com poucas atividades fora da propriedade. Parte delas trabalha na produção agrícola da propriedade, (roça e horta) e algumas trabalham na escola rural da região. As mulheres mais jovens normalmente migram para áreas urbanas na região em busca de ocupações que exigem menor qualificação.

A não exclusividade em atividades agrícolas na propriedade familiar rural é uma característica marcante. Das famílias entrevistadas, em apenas 25,92\% dos casos os integrantes trabalhavam somente na propriedade. Em 51,85\% dos núcleos familiares havia pelo menos um integrante exercendo atividade na propriedade e 
fora dela, sendo que em $71,42 \%$ dos casos esta atividade estava ligada à silvicultura. As demais atividades fora da propriedade se dividiam em prestação de serviços agrícolas para terceiros $(14,28 \%)$, trabalho em carvoaria da região $(7,15 \%)$ e trabalho na escola rural local $(7,15 \%)$.

Das 27 famílias entrevistadas apenas 55\% afirmaram que há uma época do ano com maior demanda de mão de obra, sendo que para $40 \%$ dos entrevistados ela ocorre entre agosto e novembro durante o plantio, 33\% referiram os meses de dezembro a fevereiro quando ocorre a colheita e $27 \%$ durante os meses de agosto a fevereiro no ciclo de produção.

Quanto ao manejo de produção, verifica-se que em todo o ciclo o trabalho é realizado manualmente sendo as etapas: a carpina do local, a queimada da resteva da carpina, o plantio, a carpina, a colheita, o transbordo, e o processamento (limpeza e separação dos grãos). A cultura do arroz é realizada no sistema de terras altas (cerqueiro). Para a cultura do citros é realizada apenas carpinas esporádicas e a colheita.

Os insumos utilizados na produção são sementes, herbicidas, ração a base de milho (como farelo e quirela) destinada à criação de galinhas e porcos, além do sal. As sementes utilizadas são crioulas $(56,52 \%)$, milho comercial $(13,04 \%)$, olerícolas comercias $(8,7 \%)$, crioula mais comercial para a produção de olerícolas $(13,04 \%)$ e crioula mais milho comercial $(4,35 \%)$. Para a produção citros foram utilizadas mudas comerciais. Os herbicidas são utilizados em $18,52 \%$ dos núcleos familiares e sem o acompanhamento ou instrução de técnico responsável. Respectivamente $27 \%$ e $60 \%$ dos produtores de galinhas e suínos utilizam ração à base de milho e $60 \%$ dos produtores de gado leiteiro utilizam sal comum sem suplementação. $O$ esterco curtido é utilizado em apenas um núcleo familiar.

O plantio da cultura do milho é realizado nos meses de agosto e setembro, o plantio antecipado e tardio respectivamente nos meses de junho e outubro ou de acordo com as condições climáticas. A colheita ocorre nos meses de janeiro e fevereiro e no caso do plantio antecipado e tardio nos meses de dezembro e março. O plantio da cultura do feijão ocorre no mesmo período do plantio e colheita da cultura do milho, porém em alguns casos a colheita ocorre em dezembro quando realizado o plantio em agosto. A cultura da batata doce é plantada todo ano porém 
os meses mais propícios são setembro e novembro. O plantio da cultura do arroz ocorre no mês de setembro e a colheita em fevereiro. A cana-de-açúcar é plantada em junho, o corte realizado em maio, e o tempo de permanência para a renovação da cultura não é definido.

Com relação à produção, entre as culturas outrora valorizadas e praticadas na comunidade, mas que atualmente possuem uma produção pouca expressiva ou não são mais produzidas localmente, encontram-se o alho, a cebola de raiz, a batatadoce e o rabanete. Apesar do pouco excedente de produção ainda comercializado, a cultura do citrus também enfrenta dificuldade no escoamento da produção e baixo preço o que tem levado ao abandono gradativo do cultivo.

Dentre as principais culturas exploradas em área e produção estão: feijão e milho (29\%), feijão, milho e mandioca (26\%) e, feijão, milho, mandioca e citrus (15\%). Apenas $7 \%$ das famílias produzem apenas citrus, além da produção combinada de feijão, milho, mandioca, citrus e pinus (4\%), feijão, milho, mandioca e arroz (4\%), e, feijão, milho e citrus (4\%). Pode-se observar que as principais culturas produzidas são o milho e o feijão, seguidos do cultivo da mandioca, dos citros e do pinus. $\mathrm{O}$ arroz é produzido em pequena quantidade e voltado para consumo. Já o milho, embora também seja utilizado na alimentação das famílias, sua principal finalidade é como ração para os animais.

As culturas de milho, feijão, frutíferas e algumas olerícolas são estacionais, isto é, a produção ocorre apenas em um curto período do ano. A cultura do feijão e milho são exceções, pois nestas a produção pode ser armazenada até o próximo ciclo mantendo, portanto o fornecimento mais ou menos constante durante o ano todo. Com relação aos citrus (representados pela pokan, laranja, limão e mimosa), a colheita é realizada apenas entre os meses de junho a agosto e sendo um produto perecível seu consumo restringe-se nesses meses.

Igualmente a produção de olerícolas entre as famílias da comunidade vem diminuindo no decorrer do tempo, sendo que $22 \%$ dos núcleos familiares não possuem horta dentro da propriedade. Das famílias que a mantém, observa-se uma baixa diversidade da produção, onde apenas $19 \%$ do núcleos familiares produzem mais de cinco alimentos diferentes na horta. A couve é a verdura mais cultivada sendo encontrada em $48 \%$ das famílias, seguida da alface (44\%), e do repolho, 
pepino e batata doce, todos estes encontrados nas hortas de $22 \%$ das famílias. Foram referidos ainda a abóbora (19\%) e chuchu (15\%), a cebolinha e alho ambos em $11 \%$ das famílias, a beterraba, tomate silvestre e berinjela em $7 \%$ das propriedades, além da cebola, vagem, cenoura e almeirão (4\%).

O cultivo da horta é realizado pelas mulheres da comunidade, e geralmente divide espaço dentro da propriedade familiar com o quintal da família e as árvores frutíferas. Já a roça se encontra geralmente em outra parte do terreno, mais afastada da residência das famílias. O trabalho na roça é desempenhado na maior parte das vezes pelos homens da família, mas não raro as mulheres, geralmente as esposas, ajudam no cultivo.

Quanto à produção de frutíferas, a maior parte das famílias possui variedades destas árvores no quintal da propriedade. Assim como no caso das olerícolas, apenas $19 \%$ dos núcleos apresentam mais de cinco variedades de frutíferas no terreno. As frutas identificadas foram a laranja (52\%), banana $(40 \%)$, pokan $(33 \%)$, abacate (33\%), mamão e pêssego (22\%), caqui (19\%), limão, pera e amora todas referidos em $15 \%$ das propriedades, a tangerina, jabuticaba, e maçã mencionadas em $7 \%$, e por fim o maracujá, nêspera, melancia, goiaba, abacaxi, figo e cereja todos identificados em $4 \%$ das propriedades.

A produção animal é baseada principalmente na criação de frango, seguida da criação de suínos e do gado leiteiro. Cerca de 33\% dos núcleos familiares não produzem animais com destinação a alimentação. A estrita produção avícola ocorre em $30 \%$ das propriedades realizada de forma extensiva e com o uso de ração à base de milho, tendo como objetivo o fornecimento de carne e ovos. Ocorre ainda combinada com suínos ou associada com gado leiteiro, ambas em $11 \%$ das propriedades, frango/pato em $7 \%$, além da combinação frango/gado/suínos e frango/gado/suíno/pato, todos em $4 \%$ das propriedades. Com a criação de gado a pasto visando a produção leiteira se obtêm em média quatro litros de leite de vaca por dia durante o período de pico de oito dias. Com relação à criação dos animais, $27 \%$ das famílias criam galinhas, $60 \%$ das famílias criam suínos em mangueirões utilizando ração à base de milho, e $60 \%$ dos produtores de gado leiteiro utilizam sal comum sem suplementação. Em apenas um núcleo familiar há a produção de mel a partir de abelhas do gênero Apis (com ferrão). 


\section{A COMPOSIÇÃO DOS MODELOS ALIMENTARES POSSÍVEIS}

Apesar de todas as propriedades produzirem hortaliças ou possuírem árvores frutiferas nos quintais, mediante a aplicação do questionário de frequência de consumo, registrou-se que as frutas são consumidas diariamente por 18 famílias entrevistadas $(75 \%)$ e os vegetais são consumidos diariamente por apenas 8 famílias $(33,3 \%)$.

Notou-se que entre as frutas mais consumidas diariamente estão a pokan (33\%), a laranja $(25 \%)$ e a banana (17\%), possivelmente em decorrência das mesmas estarem presentes em parte das propriedades, especialmente o cultivo de citros, devido época de produção coincidir com a pesquisa. Entre as frutas consumidas de 1 a 3 vezes por semana estão o abacate, maçã, banana, pokan, laranja, ameixa e pera. O mamão, a manga e a melancia são frutas consumidas de maneira irregular, sendo mencionado seu consumo menos de 2 vezes ao mês.

A maioria das famílias consome verduras e legumes de 1 a 3 vezes por semana. Entre os itens mais utilizados e produzidos em escalas variáveis estão a couve, a alface, o repolho, a abóbora e a batata-doce. As verduras adquiridas comercialmente são o pepino e o tomate.

O feijão cultivado amplamente pelas famílias agricultoras também é um item importante na dieta, tendo sido reportado um consumo diário em todas as famílias entrevistadas. Outra leguminosa, o amendoim, outrora de cultivo e uso muito comum na dieta local, foi mencionado o consumo esporádico na alimentação.

Analisando o consumo de cereais, pode-se identificar que o arroz é consumido diariamente em todas as famílias (e decorre de compra pois a quantidade produzida é irrelevante), seguidos pelo macarrão e o trigo que aparecem na alimentação diária de 17 famílias $(70,8 \%)$. O fubá (como é conhecida na região a farinha fina obtida pela moagem do milho) também tem presença assegurada em parte da alimentação das famílias sendo utilizada em $58,3 \%$ na frequência de 1 a 3 vezes por semana. $O$ trigo usualmente é empregado na elaboração de pães, bolos e bolinhos fritos. $O$ pão branco normalmente preparado em casa também está presente diariamente na 
alimentação de 14 famílias (58,3\%), e com frequência de 1 a 3 vezes por semana na casa de 11 famílias $(45,8 \%)$.

O milho e a mandioca, cultivados por $29 \%$ e $26 \%$ das famílias respectivamente, têm menor consumo quando comparados aos outros produtos derivados do trigo comprados em mercados locais, como por exemplo o macarrão consumido diariamente em 17 famílias, além do pão branco igualmente de uso diário por 14 famílias. A mandioca é consumida diariamente por 2 famílias, e na frequência de 3 vezes na semana por 8 famílias. Já o consumo diário do milho é citado por 9 famílias $(37,5 \%)$ e na frequência de 3 vezes por semana em 12 famílias.

Com relação ao consumo de carne, metade das famílias entrevistadas consome diariamente este item, enquanto para o restante das famílias, a carne é servida à mesa entre 1 a 3 vezes por semana. Em consonância à descrição dos arranjos produtivos, a carne de frango é a mais consumida, seguida pela carne de porco. Já a carne de gado aparece em menor escala, pois depende da compra.

O consumo diário de frango foi mencionado por $25 \%$ das famílias, enquanto os ovos (fritos, cozidos ou na culinária em geral) são usados diariamente por 8 famílias (33\%). Tanto a carne de porco quanto os embutidos são consumidos de 1 a 2 vezes por semana em 8 famílias (33\%) e o consumo da carne de gado registrado por 5 famílias $(21 \%)$. O consumo 3 vezes por semana tanto da carne de frango quanto de ovos foi identificado em 10 famílias (21\%). Este perfil de consumo se coaduna a descrição dos arranjos produtivos apresentados anteriormente de que $33 \%$ das propriedades não produzem animais com destinação para a alimentação familiar e de que há um predomínio da produção avícola associada ou não a outros animais.

Considerando a importância nutricional do leite na dieta infantil e que a maioria das famílias entrevistas tem crianças pequenas, certamente o grupo de alimentos com consumo mais problemático na comunidade refere-se ao leite e derivados. Somente 17 famílias $(70,8 \%)$ conseguem consumir alimentos desse grupo diariamente. Os registros obtidos pelo questionário de frequência indicaram que a ingestão do grupo fica restrita ao leite líquido (presente na dieta de $50 \%$ das famílias) e/ou leite em pó ( $25 \%$ das famílias). Como não há produção de gado leiteiro de maneira a suprir as necessidades de consumo, os produtos lácteos são adquiridos em mercados locais, e o consumo de queijo e iogurtes é esporádico. No 
caso de famílias titulares de direito de programa governamental destinado às crianças com idade entre 6 e 36 meses, o leite integral líquido configura o alimento mais consumido neste grupo alimentar. Ao mesmo tempo, as famílias que não participam do programa e compram leite em pó geralmente utilizam esse leite de forma mais diluída que o recomendado.

$\mathrm{Na}$ agricultura familiar, a diversidade da produção atua como fator central na obtenção de uma alimentação adequada da unidade familiar rural e a sua Segurança Alimentar depende diretamente da autonomia produtiva e dos modos específicos de reprodução social do campesinato (MENACHE, MARQUES, ZANETTI, 2008). O estudo dos arranjos produtivos articulados ao perfil de frequência no consumo de certos alimentos demonstrou uma estreita relação entre os aspectos organizacionais e econômicos da propriedade rural e a definição de modelos alimentares atestados pelas possibilidades produtivas. As modificações no perfil de produção agrícola como a redução do número de hortas, por exemplo, ou a pouca variedade produtiva implicaram na diminuição do consumo de legumes e verduras, leite e carnes. Notou-se certa monotonia alimentar em parte influenciada pela pouca diversidade na produção de alimentos, com destaque para as frutas, verduras, raízes e cereais.

\section{CONSIDERAÇÕES SOBRE A INSEGURANÇA ALIMENTAR NO CAMPO}

A pauperização de agricultores originários e tradicionais no Brasil decorre de transformações de ordem estrutural, impulsionadas pelo avanço do capital no campo, modernização técnica e pelo processo civilizatório (DELGADO, 2005; WILLEMS, 2009). O delineamento de um conjunto de dinâmicas territoriais, produtivas e sociais que daí derivam, tem levado em última instância às transformações no modo de vida no campo, das quais a alimentação e nutrição expressam a sua dimensão biológica (VALENTE, 2002; OLIVEIRA, 2002; CAUME, 2003).

Nos espaços territoriais apropriados pelos monocultivos, a aplicação de biotecnologias exógenas e capital intensivo e a proletarização, o cotidiano de certos segmentos do campesinato brasileiro, como é o caso do caboclo do Vale do Ribeira 
seguem afetados em sua organização social e produtiva. Neste movimento, certas formas de agricultura que compreendem sistemas culturais específicos vão perdendo autonomia e sendo englobadas por um modo de ordenamento do capital e do território (PLOEG, 2008).

No Vale, a migração para o trabalho assalariado, a diminuição da área de cultivo e da diversificação produtiva afetam os modelos alimentares. A alteração do perfil de produção agrícola implicou em um consumo mais restrito de legumes e verduras, carnes, cereais e raízes. Observa-se menor variedade de alimentos crioulos e caboclos presentes na alimentação das famílias e no incremento substancial de produtos ultraprocessados na dieta cotidiana. Estas imbricações entre os arranjos produtivos e os modelos alimentares representam restrições impostas ao direito de autodeterminação das populações rurais. Considerando-se que as populações caboclas expressam modos de vida particulares, práticas culturais articuladas ao território e uma economia familiar, a natureza das transformações sociais que atravessam seu cotidiano merecem ser discutidas no âmbito das políticas para a Soberania e a Segurança Alimentar no Brasil e América Latina. 


\title{
FOOD MODELS AND PRODUCTIVE ARRANGEMENTS IN THE VALE DO RIBEIRA PARANAENSE: A STUDY ON THE PRINCIPLES OF FOOD SOVEREIGNTY
}

\begin{abstract}
:
The relationship between food production and the social organization of geographic space are fundamental for the understanding of feeding practices in rural areas. This article presents a case study on the food sovereignty between family farmers of the Vale do Ribeira in the State of Parana. The study showed that the organizational aspects and economic rural property interfere in the definition of the models of food intake. The changes in agricultural production, the reduction of area planted and the little variety were responsible for the decline in consumption of vegetables, milk and meat. It was even noted some alimentary monotony on foods with emphasis on fruits, vegetables, roots, and cereals.
\end{abstract}

Keywords: Food Safety. Family Agriculture. Food models. Productive arrangements.

\section{MODELOS ALIMENTARIOS Y ARREGLOS PRODUCTIVOS EN EL VALE DO RIBEIRA PARANAENSE: UN ESTUDIO SOBRE LOS PRINCIPIOS DE LA SOBERANÍA ALIMENTARIA}

\section{Resumen:}

La relación entre mecanismos de producción, organización social y apropiación del espacio geográfico son fundamentales para la comprensión de las prácticas de alimentación en las zonas rurales. Este artículo presenta un estudio de caso sobre la soberanía alimentaria entre los agricultores caboclos de una comunidad situada en el área rural del Vale do Ribeira, en el Estado de Paraná. El estudio mostró que los aspectos organizativos y económicos de la propiedad rural interfieren en la definición de los modelos de consumo de alimentos. Los cambios en la producción agrícola, la reducción de la superficie sembrada y la poca variedad fueron los responsables de la disminución en el consumo de verduras, leche y carne. También se observó cierta monotonía de alimentación, em parte influenciada por la poca diversidad em la producción de alimentos, especialmente frutas, verduras, raíces y cereales.

Palabras clave: Seguridad alimentaria. Agricultura familiar. Modelos alimentarios. Arreglos produtivos. 


\section{REFERÊNCIAS}

ABRANDH. AÇÃO BRASILEIRA PELA NUTRIÇÃO E DIREITOS HUMANOS. Direito humano à alimentação adequada no contexto da segurança alimentar e nutricional. BURITY, V. et al. Brasília, 2010. Disponível em: http://www.redsancplp.org/uploads/5/6/8/7/5687387/dhaa no contexto da san.pdf Acesso em 29 Jan. 2015

ANTUNIASSI, M. H.; REISMANN, L. Características socioambientais da Bacia Hidrográfica do Rio Ribeira de Iguape. Cadernos CERU, série 2, n. 12, 2001.

BRANDÃO, C R. Plantar, Colher, Comer. Rio de Janeiro: Graal, 1981.

BRASIL. Lei n. 11.346, de 15 de setembro de 2006. Cria o Sistema Nacional de Segurança Alimentar e Nutricional - SISAN - com vistas em assegurar o direito humano à alimentação adequada e dá outras providências. Disponível em: http://www.planalto.gov.br/ccivil 03/ Ato2004-2006/2006/Lei/L11346.htm Acesso em 30 Dez. 2014.

. TERRITÓRIOS DA CIDADANIA. 2015. Disponível em:

http://www.territoriosdacidadania.gov.br/dotlrn/clubs/territriosrurais/xowiki/120Territori os Acesso em 29 Jan. 2015.

CAMPOS, C. S. S. Campesinato autônomo - uma nova tendência gestada pelos movimentos sociais do campo. Lutas \& Resistências, v.1, p.146 - 162, set. 2006.

CAMPOS C. S. S. CAMPOS R. Soberania alimentar como alternativa ao agronegócio no Brasil. Revista Electrónica de Geografía y Ciencias Sociales [Internet]. 2007; v. XI, n. 245. Disponível em: http://www.ub.edu/geocrit/sn/sn24568.htm Acesso em 29 Jan. 2015.

CAUME, D. J. Segurança Alimentar, Reforma Agrária e Agricultura Familiar. Revista da UFG, v. 5, n. 1, 2003. Disponível em:

http://www.proec.ufg.br/revista ufg/fome/seguranca.html

Acesso em: 29 Jan. 2015.

CONSEA. Conselho Nacional de Segurança Alimentar e Nutricional. Relatório da III Conferência Nacional de SAN. Fortaleza: Consea, 2007. Disponível em: http://www.planalto.gov.br/consea/3conferencia/Static/Documentos/Documento \%20 Final.pdf Acesso em 29 Jan. 2015. 
DELGADO, GD. A questão agrária no Brasil, 1950-2003. In: JACCOUD, L. (Org.) Questão social e políticas sociais no Brasil contemporâneo. Brasília: IPEA, 2005.

. Expansão e modernização do setor agropecuário no pós-guerra: um estudo da reflexão agrária. Estudos Avançados, v. 15, n. 43, 2001. Disponível em: http://www.scielo.br/pdf/ea/v15n43/v15n43a13.pdf Acesso em 29 Jun. 2015.

ELESBÃO, I. O espaço rural brasileiro em transformação. Finisterra, v. XLII, n. 84, p. $47-65,2007$.

FERREIRA, F. Para alimentar o mundo:modificações genéticas, (in)segurança alimentar e os riscos para a saúde humana e ambiental. Mediações, v. 17 n. 2, p. 272 - 289, Jul./Dez. 2012.

FISCHLER, C. El (h)omnívoro. El gusto, la cocina y el cuerpo. Barcelona: Editorial Anagrama. 1995.

FRAXE, TJP. Cultura cabocla ribeirinha: mitos, lendas e transculturalidade. SP: Annablume, 2004.

FREIRE, P. Educação e mudança. 25a ed. Rio de Janeiro: Paz e Terra, 2001.

FURTADO, A C. G. F. S. BEZERRA, I. Semeando a agroecologia e colhendo práticas alimentares saudáveis: um olhar sobre os faxinalenses. Demetra, v. 9, n. 1, p. $23-40,2014$.

HERNÁNDEZ, J. C. Patrimônio e Globalização: o caso das culturas alimentares. In: CANESQUI, A. M.; GARCIA, R. W. D. (orgs.) Antropologia e nutrição: um diálogo possível. Rio de Janeiro: Editora FIOCRUZ, 2005.

IPARDES. Vale do Ribeira - Referências da dinâmica regional. Curitiba, 2013. Disponível em: http://www.ipardes.gov.br/webisis.docs/vale ribeira.pdf Acesso em: 29 Jan. 2015. Instituto Paranaense de Desenvolvimento Econômico e Social. Caderno Estatístico Município de Itaperuçu, Curitiba, 2015. Disponível em 
http://www.ipardes.gov.br/cadernos/MontaCadPdf1.php?Municipio=83560\&btOk=ok Acesso em 29 Jan. 2015.

JUNGES, J. Bioética e Meio Ambiente num Contexto de América Latina. Revista Redbioética/UNESCO, v. 1, n. 9, p. 13 - 19, 2014.

MALUF, RSJ. Segurança Alimentar e Nutricional. Petrópolis: Vozes; 2007.

MARTINS, JS. A produção capitalista de relações não capitalistas de produção: o regime do colonato nas fazendas de café. In: O cativeiro da terra. São Paulo: Livraria Ed. Ciências Humanas, 1979.

MENACHE, R.; MARQUES, F. C.; ZANETTI, C. Autoconsumo e segurança alimentar: a agricultura familiar a partir dos saberes e práticas da alimentação. Revista de Nutrição PUCCAMP, v. 21, supl., p. 145-158, 2008.

MINAYO, M. C. O Desafio do Conhecimento - Pesquisa Qualitativa em Saúde. $11^{a}$ ed. São Paulo: Hucitec/Rio de Janeiro: Abrasco, 2010.

MINTZ, S. W. Comida e Antropologia. Uma breve revisão. Revista Brasileira de Ciências Sociais, v.16 n.47, p. 31 - 42, 2001.

MIRANDA, A C. MOREIRA, J C; CARVALHO, R; PERES F. Neoliberalismo, uso de agrotóxicos e a crise da soberania alimentar no Brasil. Ciência e Saúde Coletiva. Rio de janeiro, v. 12, n. 1, p. $7-14,2007$.

OLIVEIRA, A. U. A geografia agrária e as transformações territoriais recentes no campo brasileiro. In: CARLOS, A. F. (Org.). Novos Caminhos da Geografia. São Paulo: Contexto, 2002.

ONU. Pacto Internacional dos Direitos Econômicos, Sociais e Culturais. ONU, Nova York, 1966.

Disponível em: http://www.infoescola.com/direito/pacto-internacional-dos-direitoscivis-e-politicos-1966/

Acesso em 23 Set. 2015.

PEDROSO JUNIOR, N. N. et al. A casa e a roça: socioeconomia, demografia e agricultura em populações quilombolas do Vale do Ribeira, São Paulo, Brasil. 
Boletim do Museu Paraense Emílio Goeldi. Ciências humanas, v.3, n.2, p. 227 252, 2008.

POULAIN, P. Sociologias da alimentação: os comedores e o espaço social alimentar. $2^{\mathrm{a}}$ ed. Florianópolis: Editora da UFSC, 2013.

PLOEG, J. D. Camponeses e impérios alimentares: lutas por autonomia e sustentabilidade na era da globalização. Porto Alegre: UFRGS, 2008.

QUEIROZ, R. S. Caipiras negros no Vale do Ribeira: um estudo de Antropologia Econômica. SP: EDUSP, 2006.

RADOMISKY, G. F. W. LEAL O. F. Risco, sociedade e ambiente: o caso da produção ecológica cooperativa e a gestão global da biodiversidade e dos conhecimentos tradicionais. INTERthesis, v.8, n.2, p. 335 - 356, Jul./Dez. 2011.

SERAPIONI, M. Métodos qualitativos e quantitativos na pesquisa social em saúde: algumas estratégias para a integração. Ciência \& Saúde Coletiva, v. 5, n. 1, p. 187 192, 2000.

SCHRAMM, R. F. Ética ambiental e bioética global. Revista Redbioética/UNESCO, v. 1, n. 9, p. $71-78,2014$.

SCHNEIDER, S. Reflexões sobre diversidade e diversificação. Agricultura, formas familiares e desenvolvimento rural. Ruris, v. 4, n. 1, p. 81 -131, 2010.

SHANIN, T. Definição de camponês: conceituações e desconceituações. In: ESTUDOS CEBRAP. Trabalho e Dominação. Número 26. Petrópolis: Vozes, 1980.

SILVA, HÁ, MURRIETA, SRS. Mandioca, a rainha do Brasil? Ascensão e queda da Manihot esculenta no estado de São Paulo. Boletim Museu Paraense Emílio Goeldi, v. 9, n. 1, 2014. Disponível em: http://www.scielo.br/pdf/bgoeldi/v9n1/04.pdf Acesso em 29 jun. 2015.

SIMÕES, L. L.; LINO, C. F. (Orgs.). Sustentável Mata Atlântica. A exploração de seus recursos florestais. São Paulo: Editora SENAC, 2002. 
TEDESCO, J C. Modernização, patrimônio cultural e dinâmicas familiares.

Estratégias camponesas e territoriais de desenvolvimento no centro-norte do RS.

Rev. Ruris, v. 4, n. 1, 2011.

THIOLLENT. M. Metodologia de Pesquisa Participativa e Pesquisa-Ação. Rio de Janeiro: COPPE/UFPJ, 2004.

UNESCO. Declaração Universal de Bioética e Direitos Humanos. [Versão eletrônica em língua portuguesa]. 2005. Disponível em:

http://unesdoc.unesco.org/images/0014/001461/146180por.pdf

Acesso em Jan. 2015.

VALENTE, F. L. S. Do combate à fome à segurança alimentar e nutricional: o direito humano à alimentação adequada. Revista de Nutrição PUCCAMP, v. 10, n. 1, p. 20 36, jan/jun 1997.

2002 .

. Direito humano a alimentação: desafios e conquistas. São Paulo: Cortez;

WANDERLEY, M. N. B. O mundo rural como um espaço de vida. Porto Alegre:

Editora da UFRGS, 2009.

A sociologia do mundo rural e as questões da sociedade no Brasil

contemporâneo. Ruris, v. 4, n. 1 Segurança alimentar. Agricultura familiar. Modelos alimentares. Arranjos produtivos, p. 21 - 36, 2011.

WILLEMS, E. O problema rural brasileiro do ponto de vista antropológico. Tempo Social, v. 21, n. 1, 2009.

WOORTMANN, E. Herdeiros, parentes e compadres: colonos do Sul e sitiantes no Nordeste. São Paulo: Hucitec; Brasília: Editora da UnB, 1995.

Artigo

Recebido em 30 de janeiro de 2015

Aceito em 12 de setembro de 2015

R. Inter. Interdisc. INTERthesis, Florianópolis, v.12, n.2, p.156-179, Jul-Dez. 2015 